\title{
Ethanol Tolerance Affects Endogenous Adenosine Signaling in Mouse Hippocampus
}

\author{
Dali Zhang, Wei Xiong, Michael F. Jackson, and Fiona E. Parkinson \\ Department of Pharmacology and Therapeutics, University of Manitoba, and Neuroscience Research Program, Health Sciences \\ Centre, Winnipeg, Manitoba, Canada
}

Received January 20, 2016; accepted April 18, 2016

\section{ABSTRACT}

Ethanol has many pharmacological effects, including increases in endogenous adenosine levels and adenosine receptor activity in brain. Ethanol consumption is associated with both positive and negative health outcomes, but tolerance to the behavioral effects of ethanol can lead to increased consumption, which increase the risk of negative health outcomes. The present study was performed to test whether a 7-day treatment with ethanol is linked to reduced adenosine signaling and whether this is a consequence of reduced ecto-5' -nucleotidase activity. Wildtype $\left(\mathrm{CD} 73^{+/+}\right)$and ecto- $5^{\prime}$-nucleotidase-deficient $\left(\mathrm{CD} 73^{-/-}\right)$ mice were treated with ethanol $(2 \mathrm{~g} / \mathrm{kg})$ or saline for 7 days. In $\mathrm{CD}_{73^{+/+}}$mice, repeated ethanol treatment reduced the hypothermic and ataxic effects of acute ethanol, indicating the development of tolerance to the acute effects of ethanol. In $\mathrm{CD}^{+1+}$ mice, this 7-day ethanol treatment led to increased hippocampal synaptic activity and reduced adenosine $A_{1}$ receptor activity under both basal and low $\mathrm{Mg}^{2+}$ conditions. These effects of ethanol tolerance were associated with an $18 \%$ decrease in activity of ecto-5'-nucleotidase activity in hippocampal cell membranes. In contrast, ethanol treatment was not associated with changes in synaptic activity or adenosine signaling in hippocampus from $\mathrm{CD} 73^{-1-}$ mice. These data indicate that ethanol treatment is associated with a reduction in adenosine signaling through adenosine $A_{1}$ receptors in hippocampus, mediated, at least in part, via reduced ecto-5'-nucleotidase activity.

\section{Introduction}

Ethanol is widely consumed in many countries and has both positive and negative social, economic, and health consequences. In general, the negative outcomes are associated with high levels of consumption and include alcohol use disorders. One factor that can lead individuals to consume increasing quantities of ethanol is tolerance to its effects. The acute effects of ethanol in humans include euphoria, social stimulation, anxiolysis, drowsiness, slurred speech, ataxia, and impulsivity (Heinz, et al., 2011). Frequent consumption of ethanol produces functional tolerance, such that a user requires greater quantities of ethanol to produce these effects. Ethanol's effects are primarily attributed to facilitation of the inhibitory neurotransmitter GABA and inhibition of the excitatory neurotransmitter glutamate (Harris, et al., 2008). However, adenosine also contributes to the acute pharmacological effects of ethanol; in particular, the ataxia and sleep induced by ethanol are attenuated by adenosine $\mathrm{A}_{1} \mathrm{R}$ receptor antagonists (Dar, 1990, 2001; Thakkar, et al., 2010; Sharma, et al., 2014).

Ethanol enhances adenosine levels in brain (Sharma, et al., 2010b). Two mechanisms have been identified by which ethanol

Research in the authors' laboratories is funded by the Canadian Institutes for Health Research and the Natural Science and Engineering Research Council of Canada

dx.doi.org/10.1124/jpet.116.232231. increases both adenosine levels and adenosine receptor activity. First, ethanol inhibits an adenosine transporter, equilibrative nucleoside transporter 1 (ENT1) that transfers adenosine across cell membranes in a direction dictated by its concentration gradient (Nagy, et al., 1990; Allen-Gipson, et al., 2009; Kim, et al., 2011). Second, the ethanol metabolite acetate produces central nervous system (CNS) effects that are blocked by adenosine receptor antagonists (Carmichael, et al., 1991; Cullen and Carlen, 1992), and it has been proposed that metabolism of acetate to acetyl CoA produces AMP, which is further metabolized to adenosine (Carmichael, et al., 1993).

Adenosine exerts a basal inhibitory "tone" in CNS as evidenced in vivo by the adenosine receptor antagonist caffeine, a psychostimulant consumed by $80 \%$ of the world's population to increase alertness (Lara, 2010). This inhibitory adenosine tone can also be readily demonstrated in vitro; application of an adenosine $A_{1}$ receptor antagonist reverses this inhibition and facilitates glutamatergic synaptic transmission. Extracellular adenosine levels are regulated, in part, by a cascade of ectoenzymes that metabolizes extracellular adenine nucleotides (ATP, cAMP) to adenosine. Ecto-5'-nucleotidase forms adenosine from AMP and is the final enzyme in the cascade. This protein is also known as $\mathrm{CD} 73$, whereas the gene is termed 5NTE or NT5E (Zimmermann, et al., 2012).

Whereas adenosine is known to contribute to the acute effects of ethanol, adenosine levels are reduced following chronic ethanol exposure and contribute to the insomnia and seizures

ABBREVIATIONS: aCSF, artificial cerebral spinal fluid; AOPCP, $\alpha, \beta$-methylene adenosine diphosphate; BAC, blood alcohol concentration; CNS, central nervous system; CPA, N ${ }^{6}$-cyclopentyladenosine; DMSO, dimethylsulfoxide; DPCPX, 8-cyclopentyl-1,3-dipropyl-xanthine; ENT1, equilibrative nucleoside transporter 1; fEPSP, field excitatory postsynaptic potential; PPF, paired-pulse facilitation; RT-PCR, reverse-transcription polymerase chain reaction. 
associated with ethanol withdrawal (Sharma, et al., 2010a; Kim, et al., 2011). Thus, functional tolerance to ethanol may be mediated, in part, by changes in the regulation of endogenous adenosine. The present study made use of a 7-day ethanol treatment protocol and examined the effect of this treatment on synaptic activity and ecto-5' -nucleotidase activity in hippocampus.

\section{Materials and Methods}

Ethanol Treatment of Mice. Male CD73 ${ }^{+/+}$and $\mathrm{CD} 73^{-/-}$mice (C57Bl6) were housed in a dedicated mouse facility at three to four per cage, with ad libitum access to food and water, and a light/dark cycle of 12:12 with lights on at 0600 . Treatments were initiated when mice were 7-8 weeks of age. Ethanol was prepared as a $20 \%$ solution in saline. Mice were given intraperitoneal injections of ethanol $(2 \mathrm{~g} / \mathrm{kg})$ or an equivalent volume of saline. Mice were given a single injection of ethanol or injections of ethanol or saline every 24 hours for 7 days.

All procedures with animals were in accordance with guidelines set by the Canadian Council on Animal Care and approved by the University of Manitoba Animal Protocol Management and Review Committee. CD73 ${ }^{-1-}$ mice were obtained from Dr. Linda Thompson (Thompson, et al., 2004) and bred locally. Previously, we reported the absence of ecto-5'-nucleotidase activity in brain samples and cultured astrocytes from these mice (Zhang, et al., 2012; Chu, et al., 2014).

Hypothermic Response to Ethanol. Mice were familiarized with the procedure of determining body temperature by insertion of a rectal thermometer probe. On each of the three days before ethanol injection, each mouse was handled gently and given light anesthesia. The light anesthesia was used to reduce agitation. The probe of a digital thermometer was inserted $1.5 \mathrm{~cm}$ into the rectum and left in place for approximately 10 seconds until the temperature reading was stable. After ethanol treatment, mice were docile and no anesthesia was used. Body temperature was recorded at 30 and 120 minutes after the first and the seventh ethanol injection.

Ataxic Response to Ethanol. Mice, 7-8 weeks of age, were trained over 3 days to run on a rotarod for 180 seconds at $20 \mathrm{rpm}$ (Dar, 1997; Parkinson et al., 2009). All mice were successfully trained to perform this task. Mice were then injected (intraperitoneally) with $2 \mathrm{~g} / \mathrm{kg}$ ethanol and placed on the rotarod immediately and again every 15 minutes for 60 minutes. Beginning the following day, mice were injected once per day for an additional 6 days with ethanol. Immediately after the final (seventh) ethanol injection, mice were retested on the rotarod. The amount of time each mouse remained on the rotarod to a maximum of 180 seconds was measured.

Blood Alcohol Concentration. Blood samples were collected from the saphenous vein 30 and 120 minutes after a single ethanol injection or after the last of seven (one per day) ethanol injections. Blood alcohol concentration (BAC) was determined using an Analox GM7 analyzer (Analox Instruments, London, United Kingdom) following the manufacturer's protocol.

Hippocampal Slice Preparation. All hippocampal slice recordings were obtained from mice euthanized 24 hours after the last ethanol or saline injection. Mice were anesthetized with isoflurane and decapitated. Each brain was rapidly removed and placed in icecold oxygenated $\left(95 \% \mathrm{O}_{2} / 5 \% \mathrm{CO}_{2}\right.$ ) artificial cerebrospinal fluid (aCSF) of the following composition (mM): $124 \mathrm{NaCl}, 3.0 \mathrm{KCl}, 1.2 \mathrm{MgCl}_{2}, 2.0$ $\mathrm{CaCl}_{2}, 1.25 \mathrm{KH}_{2} \mathrm{PO}_{4}, 26 \mathrm{NaHCO}_{3}, 10$ D-glucose, $\mathrm{pH} 7.4$, adjusted to $285-290 \mathrm{mOsM}$. Hippocampus was removed and $350-\mu \mathrm{m}$ slices were cut using a McIlwain Tissue Chopper (Stoelting Co., Wood Dale, IL). The slices were then allowed to recover in a holding chamber for at least 1 hour at $32.5^{\circ} \mathrm{C}$ prior to electrophysiological recording.

Extracellular Recording. Individual slices were transferred to a submerged recording chamber (Harvard Apparatus, Holliston, MA) and continuously superfused with oxygenated aCSF at a flow rate of $1.5 \mathrm{ml} / \mathrm{min}$ $\left(32.5^{\circ} \mathrm{C}\right)$. Each slice was placed on a suspended nylon net to allow perfusion and oxygenation of the slice from above and below. Synaptic responses were evoked by stimulation of the Schaffer collateral/commissural pathway with a concentric bipolar stimulating electrode with 0.1-millisecond pulse width at 30 -second intervals. Extracellular field excitatory postsynaptic potentials (fEPSPs) were recorded in stratum radiatum of CA1 hippocampus using glass microelectrodes $(1-2 \Omega)$ filled with aCSF. Input/output curves were obtained by gradual increases in stimulus voltage. The baseline recording was established at 40-50\% maximal fEPSP response. At least 15-20 minutes of stable baseline was obtained in each experiment. To study paired-pulse facilitation (PPF), synaptic responses were evoked by two stimuli with 50-millisecond interpulse interval. To assess basal adenosine tone, the stimulatory effect of the adenosine $\mathrm{A}_{1}$ receptor antagonist 8-cyclopentyl-1,3-dipropylxanthine (DPCPX; $1 \mu \mathrm{M}$ ) was compared in slices from saline-treated and ethanoltreated mice. To assess the effect of ethanol treatment on epileptiformbursting synaptic activity, slices were transferred to the recording chamber and superfused with $\mathrm{Mg}^{2+}$-free aCSF for 20 minutes. The frequency of spontaneous epileptiform events was then monitored for 5 minutes. To determine whether basal adenosine levels suppress epileptiform activity the same in slices from saline-treated and ethanoltreated mice, the superfusion solution was then switched to $\mathrm{Mg}^{2+}$-free aCSF containing DPCPX $(1 \mu \mathrm{M})$. Spontaneous epileptiform activity was determined for an additional 20 minutes. Data were collected using an Axopatch 1D amplifier and analyzed using pCLAMP 10 software (Molecular Devices, Sunnyvale, CA).

To examine for changes in $\mathrm{A}_{1}$ receptor function, slices from salinetreated and ethanol-treated mice were superfused with graded concentrations of adenosine $(10-50 \mu \mathrm{M})$ or $\mathrm{N}^{6}$-cyclopentyladenosine (CPA; $1 \mathrm{nM}-1 \mu \mathrm{M})$. The maximum inhibitory response to each concentration was used to perform nonlinear regression analysis and obtain estimates of $\mathrm{IC}_{50}$ values.

Quantitative Reverse-Transcription Polymerase Chain Reaction. Hippocampus was collected from $\mathrm{CD}^{+/+}$mice 24 hours after the last injection of ethanol or saline. Total RNA was isolated, reverse transcribed, and amplified using a Bio-Rad iCycler iQ RealTime PCR Detection System as previously described (Zhang, et al., 2012). Primer sequences are provided in Table 1. Quantitative reverse-transcription polymerase chain reaction (RT-PCR) data were normalized to the corresponding $\beta$-actin values and expressed relative to gene expression in the saline-treated mice using the $2^{-\Delta \Delta \mathrm{CT}}$ method (Livak and Schmittgen, 2001).

Ecto-5' -Nucleotidase Assays. Ecto-5'-nucleotidase assays were performed as previously described (Zhang, et al., 2012). Briefly, hippocampus was collected from saline- or ethanol-treated mice 24 hours after the last injection. Cell membrane proteins (30 $\mu \mathrm{g} /$ assay) were incubated for 15 minutes at room temperature with $10 \mu \mathrm{M}\left[{ }^{14} \mathrm{C}\right] \mathrm{AMP}$ $(0.22 \mathrm{~Bq} / \mathrm{pmol})$, with or without the ecto- 5 '-nucleotidase inhibitor $\alpha, \beta$-methylene adenosine diphosphate (AOPCP; $50 \mu \mathrm{M}$ ) in a buffer containing $110 \mathrm{mM} \mathrm{NaCl}, 25 \mathrm{mM}$ glucose, $68.3 \mathrm{mM}$ sucrose, $5.3 \mathrm{mM}$ $\mathrm{KCl}, 1.8 \mathrm{mM} \mathrm{CaCl}_{2}, 1.0 \mathrm{mM} \mathrm{MgSO}_{4}$, and $20 \mathrm{mM}$ HEPES (pH 7.4). Thin-layer chromatography was used to separate $\left[{ }^{14} \mathrm{C}\right]$ adenosine, $\left[{ }^{14} \mathrm{C}\right]$ inosine, and $\left[{ }^{14} \mathrm{C}\right]$ hypoxanthine, which were then quantified by scintillation spectroscopy and expressed as picomoles produced per microgram of protein.

Drugs. DPCPX, dimethylsulfoxide (DMSO), and CPA were purchased from Sigma-Aldrich Canada Ltd. (Oakville ON). Stock solutions $(10 \mathrm{mM})$ of DPCPX and CPA were prepared in DMSO, then diluted to the final concentrations with aCSF. AOPCP was obtained from Tocris Bioscience (Bristol, UK).

Statistical Analysis. All numerical data are expressed as means \pm S.E.M. Data were tested for statistical significance with two-tailed Student's $t$ test or with one-way or two-way analysis of variance (ANOVA). A value of $p<0.05$ was considered statistically significant.

\section{Results}

$\mathrm{CD}^{-1-}$ mice have been used previously to address the source of adenosine formed in brain tissue and cultured cells during conditions such as hypoxia, ischemia, and neuronal 
TABLE 1

Primer sequences for selected mouse purinergic enzyme, transporter and receptor cDNAs.

\begin{tabular}{|c|c|c|c|}
\hline Common Name & GenBank Sequence & Primer Sequence $5^{\prime}-3^{\prime}$ & Product Size \\
\hline & & & $b p$ \\
\hline Equilibrative nucleoside transporter 1 & NM_022880.2 & CAAGTATTTCACAAACCGCCTGGAC & 196 \\
\hline & & GAAACGAGTTGAGGCAGGTGAAGAC & \\
\hline Equilibrative nucleoside transporter 2 & NM_007854.2 & $\begin{array}{l}\text { GACCTCTGCTCTTGGATACTTCAT } \\
\text { GACAACAAAGACTGAAGGTTTTCC }\end{array}$ & 288 \\
\hline Adenosine kinase (AK) & NM_134079.3 & $\begin{array}{l}\text { TGGAGCGGAACTGGGTGTTGG } \\
\text { GGAAGAGCCTGCGCCTTTTTGG }\end{array}$ & 300 \\
\hline Ecto-5'-nucleotidase (e-N) & NM_011851.4 & $\begin{array}{l}\text { GTGACCCTCCCAAGCTATCTG } \\
\text { GCTTCCCTGGTAATGACTTGC }\end{array}$ & 189 \\
\hline$A_{1}$ adenosine receptor $\left(A_{1} R\right)$ & NM_001282945.1 & $\begin{array}{l}\text { ATCGGT ACC TCC GAG TCA AGA } \\
\text { GTT GGC TAT CCA GGC TTG TTC }\end{array}$ & 167 \\
\hline$\beta$-Actin & NM_007393.3 & $\begin{array}{l}\text { GTGACGTTGACATCCGTAAA } \\
\text { CTCAGGAGGAGCAATGATCT }\end{array}$ & 148 \\
\hline
\end{tabular}

activity (Zhang, et al., 2012; Wall and Dale, 2013; Chu et al., 2014). By using this genetic mouse model we were able to circumvent the limitations inherent in the use of pharmacological tools to provide long-term in vivo inhibition of the enzyme.

Tolerance to the Acute Effects of Ethanol after a 7-day Treatment with Ethanol. A well-known effect of ethanol is a reduction in body temperature. Mice given a single injection of ethanol showed a drop in body temperature; at 30 minutes postinjection body temperature was reduced $2.2 \pm 0.1^{\circ} \mathrm{C}$ in $\mathrm{CD} 73^{+/+}$mice and $2.4 \pm 0.1^{\circ} \mathrm{C}$ in $\mathrm{CD} 73^{-/-}$mice (Fig. $1, \mathrm{~A}$ and B). This effect persisted and body temperature was still depressed by more than $1^{\circ} \mathrm{C}$ at 120 minutes postinjection. Mice that had received daily ethanol treatments showed a significantly reduced hypothermic effect following the seventh injection: body temperature was reduced by $1.7 \pm 0.03$ and $1.2 \pm 0.1^{\circ} \mathrm{C}$ at 30 and 120 minutes postinjection, respectively, in $\mathrm{CD} 3^{+/+}$mice (Fig. $1 \mathrm{~A}$ ) and $1.7 \pm 0.1^{\circ} \mathrm{C}$ and $1.1 \pm 0.2^{\circ} \mathrm{C}$ at 30 and 120 minutes postinjection, respectively, in $\mathrm{CD}^{-1-}$ mice (Fig. 1B). Thus, CD73 ${ }^{+/+}$and $\mathrm{CD} 73^{-/-}$mice showed similar body temperature responses to the first and the seventh exposure to ethanol.

Another well-known effect of ethanol is ataxia. $\mathrm{CD}^{+/+}$and $\mathrm{CD}^{-1-}$ mice given a single injection of ethanol showed a rapid and persistent decrease in motor co-ordination, as revealed by rotarod performance (Fig. 1, C and D). At 60 minutes postinjection, $\mathrm{CD} 73^{+/+}$mice showed some recovery in contrast to $\mathrm{CD} 73^{-/-}$mice. $\mathrm{CD} 73^{+/+}$mice that had received one injection of ethanol per day for 7 days exhibited a significantly greater ability to remain on the rotarod by 30 minutes. In contrast, in $\mathrm{CD} 73^{-1-}$ the start of rotarod performance recovery was delayed until 45 minutes following the last ethanol injection. Overall performance was on rotarod task was less in $\mathrm{CD} 3^{-/-}$mice compared with $\mathrm{CD} 73^{+/+}$mice (Figs. 1, C and $\mathrm{D}$, insets). After 7 days of ethanol treatment, $\mathrm{CD}^{-1-}$ mice exhibited reduced tolerance to the behavioral effects of ethanol compared with $\mathrm{CD}^{+/+}$mice.

Pharmacokinetic Ethanol Tolerance Develops with a 7-Day Ethanol Treatment. Chronic ethanol consumption can lead to altered ethanol metabolism, specifically, induction of liver microsomal enzymes, such as Cyp2E1. Enhanced ethanol metabolism can reduce the ethanol concentration in the blood and, thus, reduce the effects of ethanol. In $\mathrm{CD} 73^{+/+}$mice, blood samples were taken at 30 and 120 minutes following the first and the seventh injections of ethanol. At 30 minutes postinjection blood alcohol concentrations were identical, but at 120 minutes postinjection a $21 \%$ decrease in blood alcohol concentration was observed in mice treated for 7 days, compared with mice given a single injection (Fig. 1E). Similarly, in $\mathrm{CD} 73^{-/-}$mice treated for 7 days, blood alcohol concentrations at 30 minutes were unchanged but at 120 minutes were reduced by $21 \%$ in comparison with $\mathrm{CD}^{-/-}$mice receiving a single ethanol injection (Fig. 1F).

Ethanol Treatment Increases Basal Synaptic Activity in $\mathrm{CD}^{+/+}$but Not $\mathrm{CD}^{-/-}$Mice. $\mathrm{CD}^{-/+}$and $\mathrm{CD} 73^{-1-}$ mice were given saline or ethanol every 24 hours for 7 days, then hippocampal slices were prepared 24 hours after the last injection. Using fEPSP recordings, we first generated input-output curves and found an increase in basal synaptic transmission in response to stimulus intensities greater than $2.8 \mathrm{~V}$ in slices from ethanol-treated $\mathrm{CD}^{+/+}$ mice, compared with slices from saline-treated mice (Fig. 2A). Next, we examined PPF, in which two electrical pulses were delivered in 50 milliseconds. PPF is increased in the presence of adenosine or adenosine $A_{1}$ receptor agonists and is decreased by adenosine removal or $\mathrm{A}_{1}$ receptor antagonists (Dunwiddie and Haas, 1985; Brust, et al., 2007; Chen, et al., 2014). We found reduced PPF in slices from ethanol-treated, relative to saline-treated $\mathrm{CD} 73^{+/+}$mice (Fig. 2C). In contrast, input-output curves and PPF were not altered in slices from ethanol-treated, compared with saline-treated $\mathrm{CD} 73^{-/-}$mice (Fig. 2, B and D).

Ethanol Treatment Is Associated with Reduced Adenosine Tone in $\mathbf{C D 7 3}^{+/+}$Mice. To address whether the altered basal synaptic transmission in slices from ethanoltreated $\mathrm{CD}^{+/+}$mice was associated with changes in basal adenosine $\mathrm{A}_{1}$ receptor activity, we used the selective adenosine $A_{1}$ receptor antagonist DPCPX $(1 \mu \mathrm{M})$. DPCPX increased fEPSP slope in slices from both ethanol-treated and salinetreated $\mathrm{CD} 3^{+/+}$mice but had a significantly greater effect in slices from saline-treated mice (Fig. 2E). In contrast, DPCPX had a similar stimulatory effect in slices from both ethanoltreated and saline-treated $\mathrm{CD}^{-1-}$ mice (Fig. 2F).

Epileptiform-bursting synaptic activity was evaluated in hippocampal slices superfused with $\mathrm{Mg}^{2+}$-free aCSF before and during DPCPX application (Fig. 3). In slices from $\mathrm{CD}^{+/+}$ mice, a significant increase in bursting activity was observed in slices from ethanol-treated compared with slices from saline-treated mice (Fig. 3C). This was not observed between slices from ethanol-treated and saline-treated $\mathrm{CD}^{-1-}$ mice (Fig. 3G). Application of DPCPX (1 $\mu \mathrm{M})$ stimulated epileptiformbursting activity in slices from both $\mathrm{CD} 73^{+/+}$and $\mathrm{CD} 73^{-/-}$mice 
A

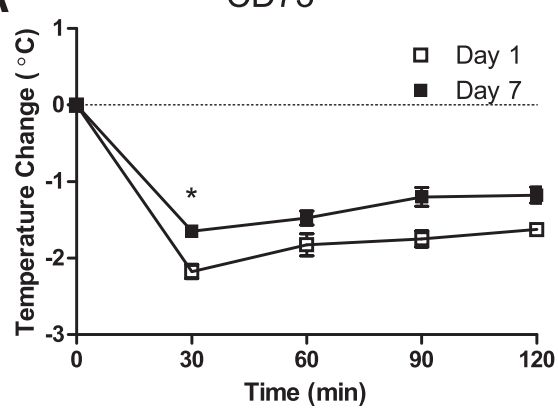

C

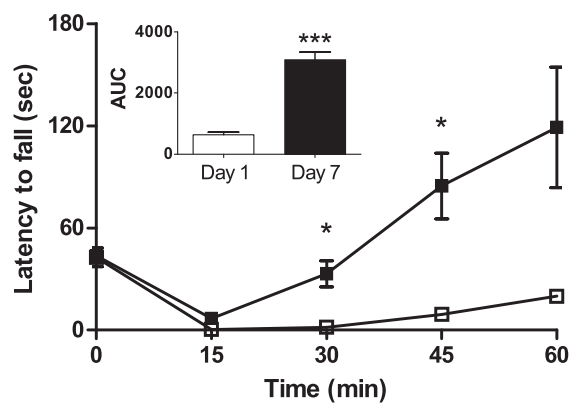

E

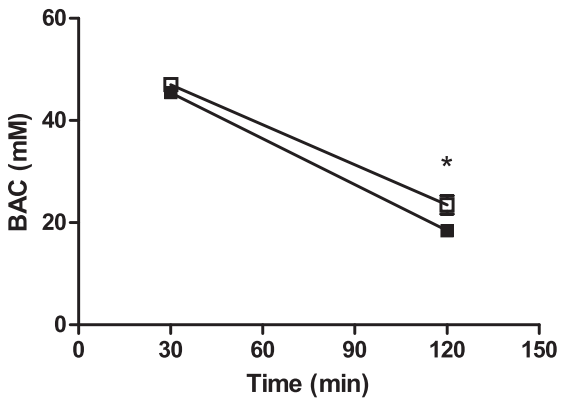

B

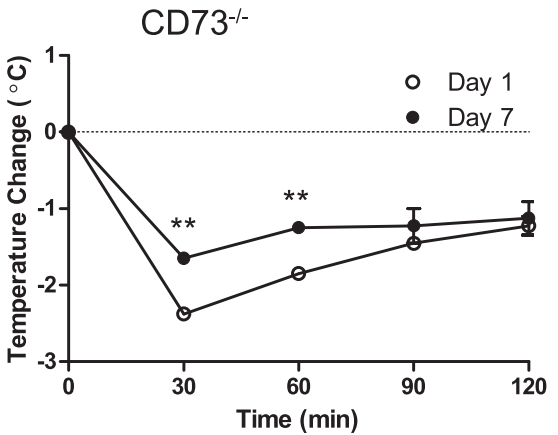

D

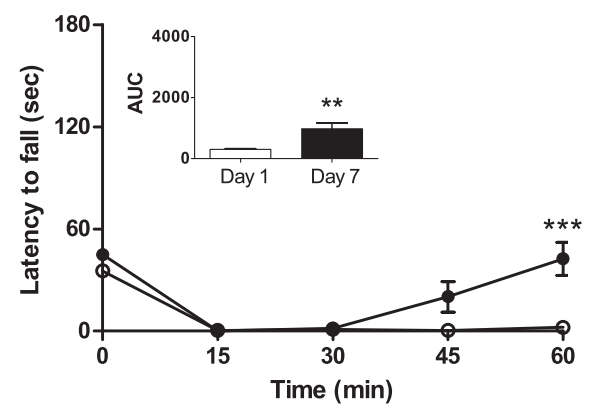

$\mathbf{F}$

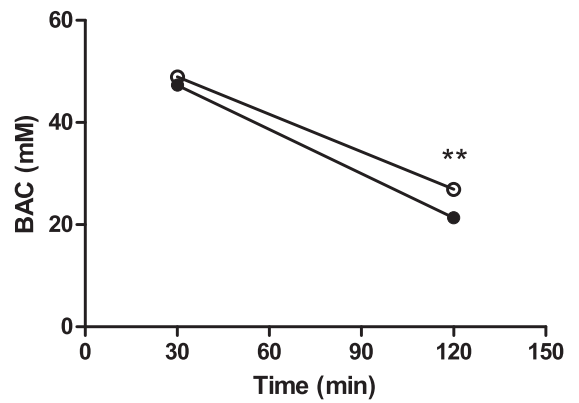

Fig. 1. Tolerance to acute effects of ethanol. $\mathrm{CD}^{1+/+}(\mathrm{A}, \mathrm{C}, \mathrm{E})$ and $\mathrm{CD} 73^{-/-}(\mathrm{B}, \mathrm{D}$, F) mice were treated with ethanol $(2 \mathrm{~g} / \mathrm{kg}$, i.p.) once (Day 1), or every 24 hours for 7 days (Day 7). The hypothermic response $(\mathrm{A}, \mathrm{B})$ and the motor ataxic response $(\mathrm{C}, \mathrm{D})$ to ethanol was compared between mice receiving their first or their seventh dose of ethanol. Insets: area under the curve (AUC). (E, F) Blood alcohol concentrations (BAC) were determined in mice 30 or 120 minutes after receiving a single ethanol injection or a seventh injection. Data are means \pm S.E.M.; note that in some cases the error bars are obscured by the symbols. $n=4(\mathrm{~A}, \mathrm{~B}, \mathrm{C}, \mathrm{F})$ or $8(\mathrm{D}, \mathrm{E}) . * P<$ $0.05, * * P<0.01, * * * P<0.001$; two-tailed paired (A-D) or unpaired (E, F) $t$ tests.
(Fig. 3D, H), indicating the presence of endogenous adenosine and activation of $\mathrm{A}_{1}$ receptors. Beginning 5 minutes after application of DPCPX, epileptiform-bursting was significantly greater in slices from saline-treated compared with ethanoltreated $\mathrm{CD} 73^{+/+}$mice (Fig. 3D). In contrast, no significant difference in the response to DPCPX was observed between slices from saline-treated and ethanol-treated $\mathrm{CD}^{-1-}$ mice (Fig. 3H).

Ethanol Treatment Reduced Inhibitory Responses to Adenosine, but Not the Adenosine $A_{1}$ Receptor Agonist CPA, in Slices from $\mathbf{C D 7 3}^{+/+}$Mice. To test whether a 7-day ethanol treatment is associated with changes in the inhibitory potency of adenosine or the selective $A_{1}$ receptor agonist CPA, fEPSPs were recorded from slices treated with graded concentrations of adenosine $(10-50 \mu \mathrm{M})$ or CPA (1 nM-1 $\mu \mathrm{M}$ ) (Fig. 4, A and B). The inhibitory effect of adenosine, but not CPA, showed a small reduction in slices from ethanol-treated mice. For each purine, the maximum inhibition observed at each concentration was determined and nonlinear regression analysis was performed to obtain estimates of the concentrations producing responses $50 \%$ of baseline $\left(\mathrm{IC}_{50}\right.$ values). For adenosine, $\mathrm{IC}_{50}$ values $(95 \%$ confidence intervals) were $26(22-29) \mu \mathrm{M}$ and $34(30-40) \mu \mathrm{M}$ for slices from saline-treated and ethanol-treated mice, respectively.
For CPA, $\mathrm{IC}_{50}$ values were 22 (16-29) $\mathrm{nM}$ and 25 (18-35) $\mathrm{nM}$ for slices from saline-treated and ethanol-treated mice, respectively. Thus, adenosine but not CPA showed a small but significant difference in inhibitory potency between hippocampal slices from saline-treated and ethanol-treated $\mathrm{CD}^{+/+} 3^{+/}$mice.

Ethanol Treatment Did Not Have a Significant Effect on Gene Expression of Adenosine $A_{1}$ Receptors, Nucleoside Transporters, or Purinergic Enzymes in Hippocampal Tissue from $\mathrm{CD}^{+/+}$Mice. Quantitative RT-PCR data from hippocampus isolated from saline- and ethanol-treated $\mathrm{CD} 73^{+/+}$mice was normalized to their respective $\beta$-actin values and expressed relative to salinetreated gene expression using the $2^{-\Delta \Delta \mathrm{CT}}$ method (Livak and Schmittgen, 2001). Ethanol treatment was not associated with statistically significant changes in gene expression of adenosine $A_{1}$ receptors ENT1, ENT2, adenosine kinase, or ecto-5' nucleotidase, although a trend (repeated-measures ANOVA, $P=0.04$; no statistically significant differences were detected with Dunnet's multiple comparison post-tests) toward reduced expression of ecto-5' -nucleotidase was noted (Fig. 5A).

Given the trend toward a decrease in expression of ecto- $5^{\prime}$ nucleotidase, ecto- $5^{\prime}$-nucleotidase assays were performed. An $18 \%$ decrease in ecto- 5 '-nucleotidase activity in hippocampus from ethanol-treated, relative to saline-treated, mice was 
A

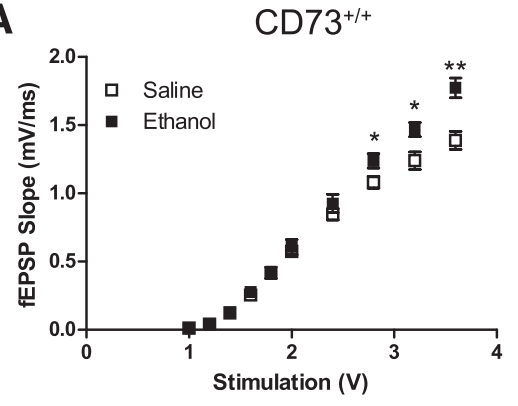

C
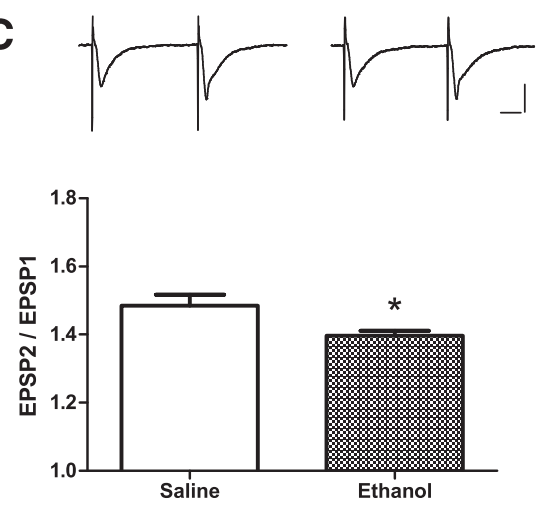

E
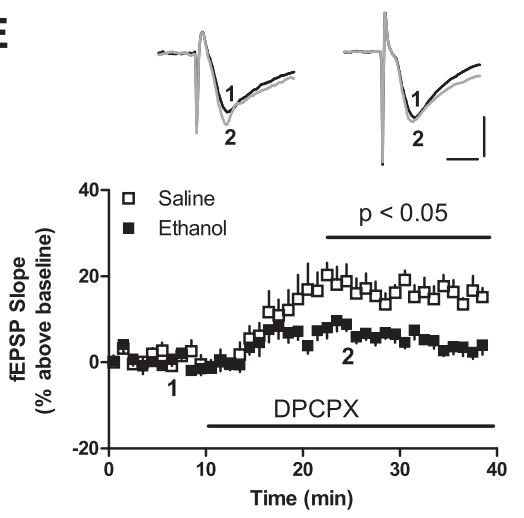

B

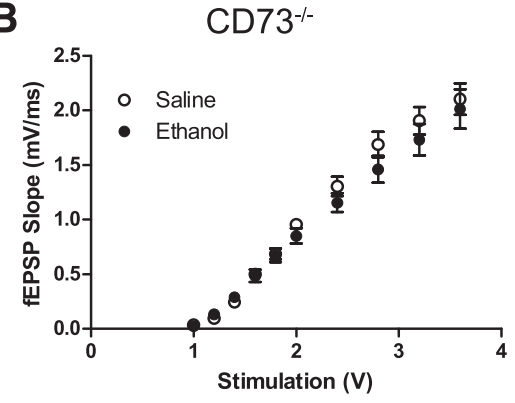

D
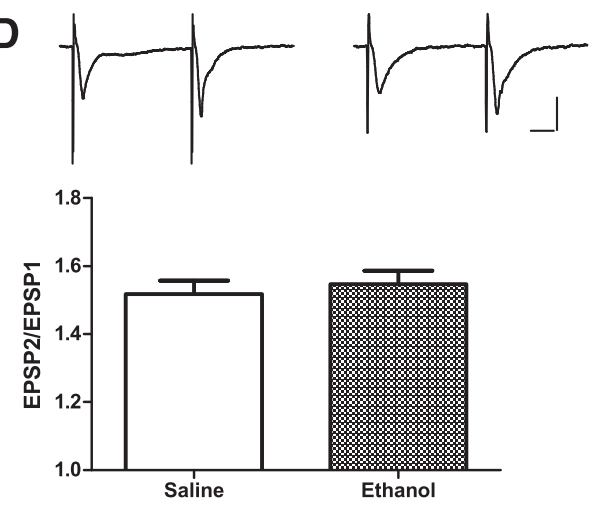

$\mathbf{F}$
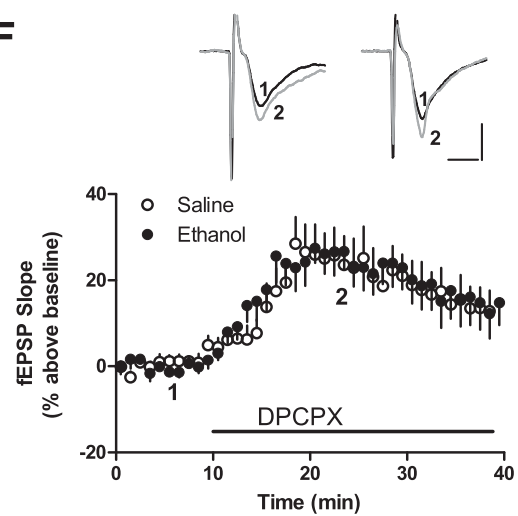

Fig. 2. Altered presynaptic transmission in hippocampal slices from saline-treated and ethanol-treated mice. Slices were prepared from $\mathrm{CD}^{+/+}(\mathrm{A}, \mathrm{C}, \mathrm{E})$ and $\mathrm{CD}^{-1-}(\mathrm{B}, \mathrm{D}, \mathrm{F})$ mice 24 hours after the last injection. (A, B) Basal transmission constructed by input-output curves. (C, D) PPF determined with 50-millisecond inter-pulse intervals. Representative traces (left: saline-treated; right: ethanol-treated) are shown; calibration bars are $0.5 \mathrm{mV}$ and 10 milliseconds. (E, F) Effect of DPCPX $(1 \mu \mathrm{M})$ on fEPSP recordings. DPCPX was superfused as indicated by the horizontal bar. For slices from saline-treated CD73 ${ }^{+/+}$ mice, data were significantly different from 22.5 minutes until data collection was terminated. Representative traces (left: saline-treated; right: ethanol-treated) are shown; 1-black, before DPCPX; 2-gray, during DPCPX exposure; calibration bars are $0.5 \mathrm{mV}$ and 5 milliseconds. $n=6$ $(\mathrm{A}-\mathrm{D})$ or $5(\mathrm{E}, \mathrm{F}) . * P<0.05 ; * * P<0.01$, two-tailed $t$ test. observed (Fig. 5B). Specificity of the assay was verified by the $78-82 \%$ inhibition of adenosine formation in the presence of $\mathrm{AOPCP}$, an inhibitor of ecto-5'-nucleotidase, and the low levels of inosine and hypoxanthine produced.

\section{Discussion}

The main findings of this study were that treatment with ethanol ( $2 \mathrm{~g} / \mathrm{kg}$ per day, i.p.) for 7 days was associated with a degree of tolerance to the acute hypothermic and ataxic effects of ethanol in both $\mathrm{CD}^{+/+}$and $\mathrm{CD} 73^{-/-}$mice, whereas increased basal synaptic activity and reduced basal inhibitory adenosine tone were observed in hippocampus of $\mathrm{CD} 73^{+/+}$mice but not in $\mathrm{CD} 73^{-/-}$mice. This evidence for an important role of ecto-5'-nucleotidase was supported by the observation that ecto-5'-nucleotidase activity was significantly reduced in hippocampus isolated from $\mathrm{CD}^{+/+}$mice treated with ethanol.

Although low levels of ethanol consumption are associated with health benefits, high levels of consumption are associated with adverse health outcomes, including cancers, liver damage, and alcohol use disorders. Chronic use of ethanol is associated with both functional and pharmacokinetic tolerance. Increasing levels of tolerance to the effects of ethanol can lead to further increases in ethanol consumption and, therefore, increased risk of adverse health outcomes. Addressing the mechanisms that underlie tolerance could, in principle, slow or prevent dose escalation and reduce the risk of ethanollinked health concerns. As some reports indicate that reduced adenosine signaling is involved in alcohol withdrawal and relapse (Sharma, et al., 2010a; Kim, et al., 2011), the present study was undertaken to address whether a 7-day ethanol treatment is associated with altered adenosine signaling.

Many animal models have been developed for studies of alcohol use disorders (Plackett and Kovacs, 2008; Knapp and Breese, 2012). In the present study, ethanol was administered to mice by intraperitoneal injection. This was to ensure that all animals received the same dose, had reproducible profiles of blood alcohol levels, and blood alcohol levels dropped to zero between doses. The peak blood levels measured were about $42 \mathrm{mM}$, or $180 \mathrm{mg} / \mathrm{dl}$ (180 mg\%), which, depending on 


\section{$\mathrm{CD}^{+/ /+}$}

A

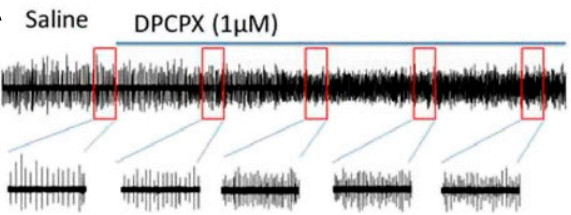

B Ethanol DPCPX (1 $1 \mu \mathrm{M})$

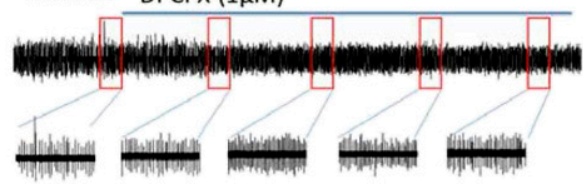

C

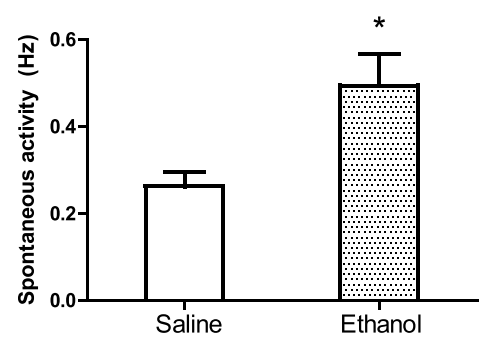

D

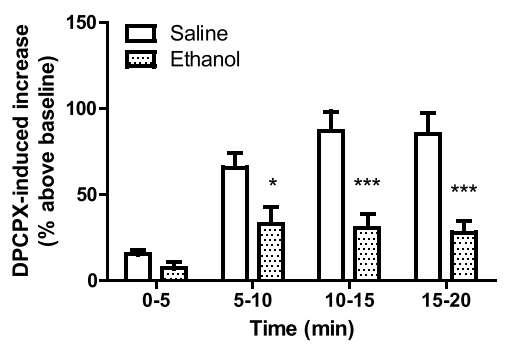

$\mathrm{CD} 73^{-1}$

E

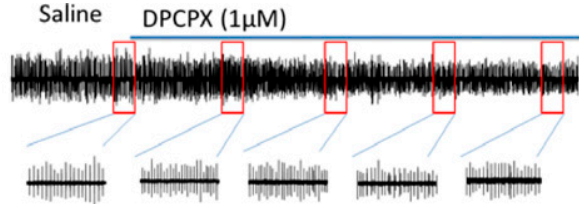

F Ethanol $\operatorname{DPCPX}(1 \mu \mathrm{M})$

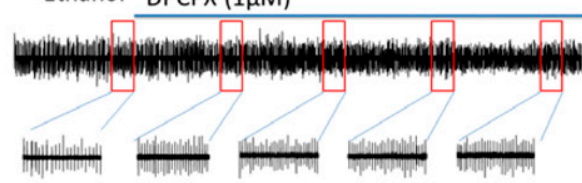

G

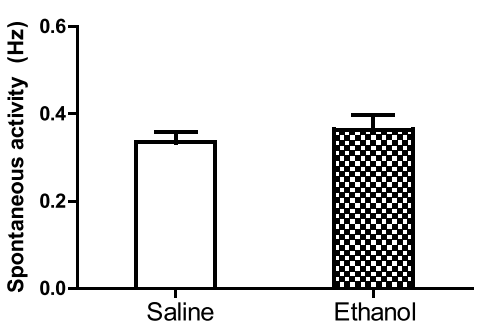

H

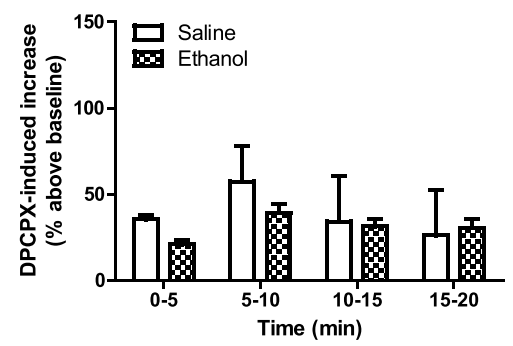

Fig. 3. Epileptiform-bursting synaptic activity in hippocampal slices from ethanol-treated and saline-treated $\mathrm{CD}^{+/+}$and $\mathrm{CD} 73^{-/-}$mice. Mice were treated with saline or ethanol $(2 \mathrm{~g} / \mathrm{kg}$, i.p.) every 24 hours for 7 days. Hippocampal slices were prepared 24 hours after the last injection. Slices were superfused with $\mathrm{Mg}^{2+}$-free aCSF for 5 minutes then with $\mathrm{Mg}^{2+}$-free aCSF containing DPCPX $(1 \mu \mathrm{M})$ for an additional 20 minutes, and epileptiform-bursting activity was recorded. Representative traces are shown from individual slices from saline-treated $\mathrm{CD}^{+/+}$(A) and $\mathrm{CD}^{+/-}$(E) mice and from ethanol-treated $\mathrm{CD}^{+/+}(\mathrm{B})$ and $\mathrm{CD}_{73^{-1-}}(\mathrm{F})$ mice. The boxed regions are expanded as indicated and represent 1-minute intervals before and during DPCPX application. (C, G) fEPSPs were counted for 5 minutes and reported as events per second $(\mathrm{Hz})$, and a significant increase in epileptiform-bursting was observed only in slices from ethanol-treated $\mathrm{CD} 3^{+/+}$ mice. (D, H) After the addition of DPCPX, fEPSPs were counted, in 5-minute bins, for an additional 20 minutes. DPCPX produced a greater stimulation of epileptiform-bursting in salinetreated than in ethanol-treated slices from $\mathrm{CD} 73^{+/+}$mice. $n=5(\mathrm{C}, \mathrm{D})$ or $4(\mathrm{G}$, H). $* P<0.05$ for two-tailed $t$ test (C); $* P<0.05 ; * * * P<0.001$ for saline versus ethanol treatment; two-way ANOVA (D) jurisdiction, exceeds by 2- to 3 -fold the legal level allowed for a human operating a motor vehicle. Thus, the profile of blood alcohol levels in the present study shows a general similarity to binge drinking, a risk factor for alcohol use disorders and alcohol-linked adverse health outcomes in humans (Crabbe, et al., 2011).

In this study, all animals exhibited hypothermic and ataxic responses to ethanol, with a modest level of tolerance evident after 7 days of ethanol treatment. In principle, increased ethanol metabolism, by reducing blood alcohol levels, could reduce responses to acute ethanol. A degree of pharmacokinetic tolerance was observed; however, peak plasma levels determined 30 minutes postinjection were not significantly different between mice receiving their first or their seventh ethanol injection. Therefore, the observed tolerance to the hypothermic and ataxic effects of ethanol, observed within 30-45 minutes of ethanol injection, was probably not simply the result of enhanced ethanol metabolism in mice treated for 7 days.

Given the previous observations that adenosine contributes to acute effects of ethanol, we sought to determine if adenosine signaling is altered by a 7-day treatment of repeated ethanol exposure. Although several reports describe a contribution of adenosine to acute hypothermic and ataxic effects (Dar, 1990, 2001; Naassila et al., 2002; Parkinson et al., 2009), we used these assays simply to validate that ethanol tolerance was clearly induced by our treatment protocol. The mechanisms that underlie ethanol tolerance to hypothermia and ataxia were not addressed. Instead, we focused on adenosine signaling in hippocampal slices, because this brain region retains viable neuronal networks after dissection and allows the effects of adenosine on synaptic activity to be measured. Furthermore, this brain region is altered by chronic ethanol exposure, and ethanol withdrawal can trigger seizure activity in susceptible individuals (Stepanyan, et al., 2008), which is linked to increased presynaptic neurotransmitter release and increased postsynaptic $N$-methyl-D-aspartate receptor activation (Hendricson, et al., 2007).

Endogenous adenosine, acting at $\mathrm{A}_{1}$ receptors in hippocampal slices, reduces glutamatergic excitatory synaptic transmission, resulting in reduced input-output relations, increased PPF, and suppressed epileptiform-bursting (Dunwiddie and Haas, 1985; Brust, et al., 2007; Etherington, et al., 2009; Chen, et al., 2014). In slices from $\mathrm{CD} 73^{+/+}$mice, ethanol treatment was associated with an increased input-output relationship, a decreased PPF, an increase in epileptiform-bursting, and an attenuated excitatory effect of DPCPX, indicating a reduced level of endogenous adenosine and reduced basal activation of $\mathrm{A}_{1}$ receptors in $\mathrm{CD} 73^{+/+}$mice treated for 7 days with ethanol.

Increased excitability and a link to reduced basal adenosine tone was observed in $\mathrm{CD}^{+/+}$but not in $\mathrm{CD}^{+1-}$ mice. Previously, we reported that in this strain of $\mathrm{CD}^{-1-}$ mice 
A
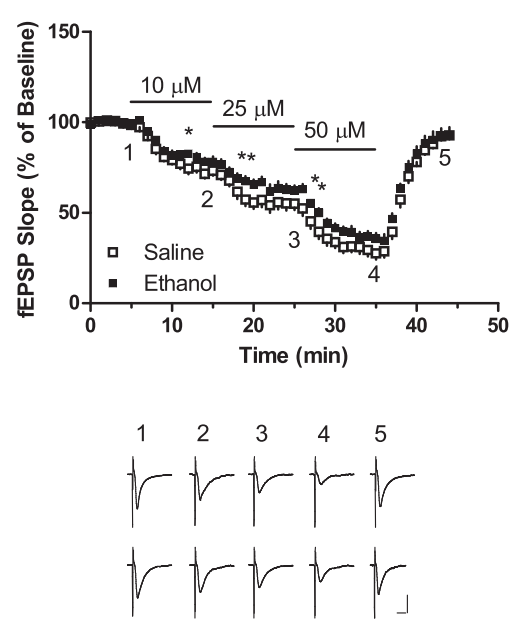

B CPA

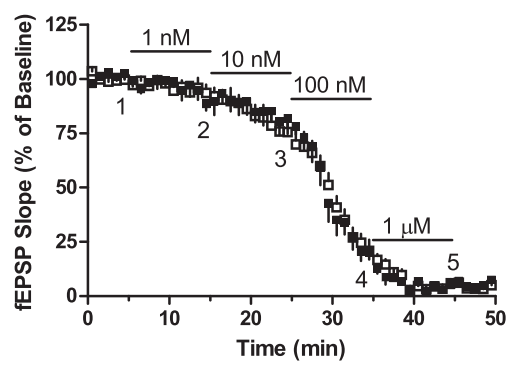

$\sqrt[3]{\sqrt[3]{4}}$
Fig. 4. Inhibition by adenosine or CPA of fEPSP recordings in hippocampal slices from mice injected (intraperitoneal) with saline or ethanol ( $2 \mathrm{~g} / \mathrm{kg}$ ) every 24 hours for 7 days. Hippocampal slice recordings were obtained 24 hours after the last injection. Graded concentrations of adenosine or CPA were superfused as indicated by the horizontal lines. Representative traces at the times indicated are illustrated. Calibration bars correspond to $0.5 \mathrm{mV}$ and 10 milliseconds. $n=10(\mathrm{~A})$ or $5(\mathrm{~B}) . * P<0.05$, two-tailed $t$ test. other mechanisms such as tissue nonspecific alkaline phosphatase appear to compensate, in part, for the loss of ecto-5'nucleotidase (Zhang, et al., 2012), and this may explain why adenosine tone in slices stimulated at a very low rate $(0.033 \mathrm{~Hz})$ was not reduced in slices from $\mathrm{CD}^{-1-}$ mice (see Fig. 2F). Interestingly, in an independent strain of $\mathrm{CD}^{-1-}$ mice, a change in tissue-nonspecific alkaline phosphatase was not observed (Langer, et al., 2008). A low $\mathrm{Mg}^{2+}$ buffer increased neuronal activity to $>0.2 \mathrm{~Hz}$ in slices from both saline-treated and ethanol-treated $\mathrm{CD}_{73^{+/+}}$and $\mathrm{CD}^{-/-}$mice (see Fig. 3, C and G). As the stimulatory effect of DPCPX, a measure of adenosine levels, was greater in slices from saline-treated $\mathrm{CD} 73^{+/+}$mice than in slices from saline-treated $\mathrm{CD}^{-1-}$ mice, ecto-5'-nucleotidase appears to be important for the formation of endogenous adenosine in this condition of high neuronal activity, even if other mechanisms can compensate for its absence at low levels of activity. As revealed by DPCPX, the production of adenosine by low $\mathrm{Mg}^{2+}$-induced neuronal activity was attenuated in slices from ethanol-treated $\mathrm{CD}^{+/+}$and was similar to that observed in low $\mathrm{Mg}^{2+}$-treated slices from salinetreated and ethanol-treated CD73 ${ }^{-1-}$ mice (see Fig. 3, D and H).

In hippocampal slice preparations from ethanol-treated $\mathrm{CD} 73^{+/+}$mice, we observed a small reduction in the inhibitory effect of exogenous adenosine. The net response is attributable to the exogenous plus endogenous adenosine and, thus, is reduced as a direct result of the reduced contribution of endogenous adenosine in slices from ethanol-treated, compared with saline-treated, CD73 ${ }^{+/+}$mice. This reduced inhibitory effect of adenosine and reduced adenosine tone in slices from ethanol-treated $\mathrm{CD} 73^{+/+}$mice could be explained by reduced adenosine formation, reduced adenosine $\mathrm{A}_{1}$ receptor activity, or increased adenosine clearance. However, ethanol treatment did not affect the responses to the exogenous $\mathrm{A}_{1}$ receptor agonist $\mathrm{CPA}$ and did not affect gene expression of adenosine $\mathrm{A}_{1}$ receptors, indicating that these receptors are not regulated in this model of ethanol tolerance. Adenosine influx mediated by ENT1 and/or ENT2 and intracellular metabolism by adenosine kinase in astrocytes constitutes the predominant clearance pathway for adenosine in CNS (Boison, 2012). Gene expression of these transporters and this enzyme was also not affected in ethanol tolerance.

A trend toward a reduction in expression of ecto-5' nucleotidase and a significant decrease in ecto-5'-nucleotidase activity was observed in hippocampal tissue from ethanoltreated $\mathrm{CD}^{+/+}$mice. This, together with the absence of an effect of ethanol treatment on adenosine levels in hippocampal
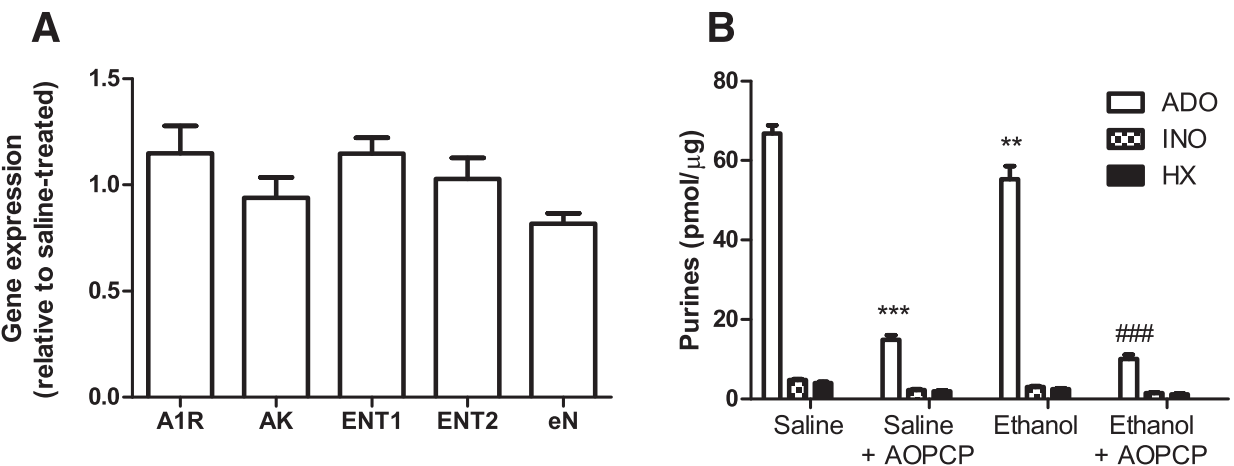

Fig. 5. Relative expression of purinergic genes and activity of ecto-5'-nucleotidase. CD73 ${ }^{-/-}$mice were treated with saline or ethanol (2 g/kg, i.p.) every 24 hours for 7 days. Hippocampus was collected 24 hours after the last injection. (A) Total RNA was isolated and used for quantitative RT-PCR. Expression of adenosine $A_{1}$ receptors $\left(A_{1} R\right)$, adenosine kinase $(A K)$, equilibrative nucleoside transporters 1 and 2 and ecto-5'-nucleotidase (eN) was determined. Gene expression was normalized to actin and expression in ethanol-treated, relative to saline-treated samples is shown. Data were analyzed by repeated measures ANOVA $(P=0.04)$ with Dunnet's multiple comparison post tests. (B) Hippocampal cell membranes were isolated and incubated with $\left[{ }^{14} \mathrm{C}\right] \mathrm{AMP}$ in the presence or absence of AOPCP $(50 \mu \mathrm{M})$ and the formation of $\left[{ }^{14} \mathrm{C}\right]$ labeled adenosine (ADO), inosine (INO), and hypoxanthine (HX) was quantified. $* * P<$

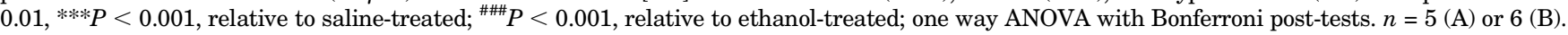


tissue from $\mathrm{CD}^{-1-}$ mice, indicates that regulation of ecto-5' nucleotidase plays an important role in the attenuation of adenosinergic mechanisms that is associated with repeated ethanol exposure. Further studies are required to investigate the mechanisms by which ethanol treatment reduces ecto-5'nucleotidase activity.

In summary, whereas ethanol has multiple pharmacological targets and several mechanisms that contribute to ethanol tolerance, this study has demonstrated that 7 days of repeated ethanol treatment attenuated the increases in adenosine that are induced by neuronal activity. Specifically, in hippocampus both isolated ecto- 5 '-nucleotidase activity and ecto-5'-nucleotidase activity associated with neuronal excitation were reduced following 7 days of ethanol exposure. Of note, as tolerance to hypothermic effects of ethanol were similar in $\mathrm{CD}^{+/+}$and $\mathrm{CD} 73^{-/-}$mice, altered ecto-5' ${ }^{\prime}$-nucleotidase activity contributes to some but not all signs of ethanol tolerance. Elucidation of the specific mechanisms that underlie ethanol-induced changes, and comparison of these changes in different brain regions and cell types, may reveal strategies to mitigate or treat ethanol tolerance.

\section{Authorship Contributions}

Participated in research design: Parkinson, Zhang, Jackson, Xiong. Conducted experiments: Zhang, Xiong.

Performed data analysis: Parkinson, Zhang, Xiong.

Wrote or contributed to the writing of the manuscript: Parkinson, Jackson.

\section{References}

Allen-Gipson DS, Jarrell JC, Bailey KL, Robinson JE, Kharbanda KK, Sisson JH, and Wyatt TA (2009) Ethanol blocks adenosine uptake via inhibiting the nucleoside transport system in bronchial epithelial cells. Alcohol Clin Exp Res 33: $791-798$.

Boison D (2012) Adenosine dysfunction in epilepsy. Glia 60:1234-1243.

Brust TB, Cayabyab FS, and MacVicar BA (2007) C-Jun N-terminal kinase regulates adenosine A1 receptor-mediated synaptic depression in the rat hippocampus. Neuropharmacology 53:906-917.

Carmichael FJ, Israel Y, Crawford M, Minhas K, Saldivia V, Sandrin S, Campisi P, and Orrego $H$ (1991) Central nervous system effects of acetate: contribution to the central effects of ethanol. $J$ Pharmacol Exp Ther 259:403-408.

Carmichael FJ, Orrego H, and Israel Y (1993) Acetate-induced adenosine mediated effects of ethanol. Alcohol Alcohol Suppl 2:411-418.

Chen Z, Xiong C, Pancyr C, Stockwell J, Walz W, and Cayabyab FS (2014) Prolonged adenosine $\mathrm{A} 1$ receptor activation in hypoxia and pial vessel disruption focal cortical ischemia facilitates clathrin-mediated AMPA receptor endocytosis and long-lasting synaptic inhibition in rat hippocampal CA3-CA1 synapses: differential regulation of GluA2 and GluA1 subunits by p38 MAPK and JNK $J$ Neurosci 34:9621-9643.

Chu S, Xiong W, and Parkinson FE (2014) Effect of ecto-5'-nucleotidase (eN) in astrocytes on adenosine and inosine formation. Purinergic Signal 10:603-609.

Crabbe JC, Harris RA, and Koob GF (2011) Preclinical studies of alcohol binge drinking. Ann N Y Acad Sci 1216:24-40.

Cullen N and Carlen PL (1992) Electrophysiological actions of acetate, a metabolite of ethanol, on hippocampal dentate granule neurons: interactions with adenosine. Brain Res 588:49-57.

Dar MS (1990) Central adenosinergic system involvement in ethanol-induced motor incoordination in mice. $J$ Pharmacol Exp Ther 255:1202-1209.

Dar MS (1997) Mouse cerebellar adenosinergic modulation of ethanol-induced motor incoordination: possible involvement of cAMP. Brain Res 749:263-274.
Dar MS (2001) Modulation of ethanol-induced motor incoordination by mouse striatal A(1) adenosinergic receptor. Brain Res Bull 55:513-520.

Dunwiddie TV and Haas HL (1985) Adenosine increases synaptic facilitation in the in vitro rat hippocampus: evidence for a presynaptic site of action. J Physiol 369:365-377. Etherington LA, Patterson GE, Meechan L, Boison D, Irving AJ, Dale N, and Frenguelli BG (2009) Astrocytic adenosine kinase regulates basal synaptic adenosine levels and seizure activity but not activity-dependent adenosine release in the hippocampus. Neuropharmacology 56:429-437.

Harris RA, Trudell JR, and Mihic SJ (2008) Ethanol's molecular targets. Sci Signal 1: re7.

Heinz AJ, Beck A, Meyer-Lindenberg A, Sterzer P, and Heinz A (2011) Cognitive and neurobiological mechanisms of alcohol-related aggression. Nat Rev Neurosci 12: $400-413$

Hendricson AW, Maldve RE, Salinas AG, Theile JW, Zhang TA, Diaz LM, and Morrisett RA (2007) Aberrant synaptic activation of N-methyl-D-aspartate receptors underlies ethanol withdrawal hyperexcitability. J Pharmacol Exp Ther 321:60-72.

Kim JH, Karpyak VM, Biernacka JM, Nam HW, Lee MR, Preuss UW, Zill P, Yoon G, Colby C, and Mrazek DA, et al. (2011) Functional role of the polymorphic $647 \mathrm{~T} / \mathrm{C}$ variant of ENT1 (SLC29A1) and its association with alcohol withdrawal seizures. PLoS One 6:e16331.

Knapp DJ and Breese GR (2012) Models of chronic alcohol exposure and dependence. Methods Mol Biol 829:205-230.

Langer D, Hammer K, Koszalka P, Schrader J, Robson S, and Zimmermann H (2008) Distribution of ectonucleotidases in the rodent brain revisited. Cell Tissue Res 334: 199-217.

Lara DR (2010) Caffeine, mental health, and psychiatric disorders. J Alzheimers Dis 20 (Suppl 1):S239-S248.

Livak KJ and Schmittgen TD (2001) Analysis of relative gene expression data using real-time quantitative PCR and the 2(-Delta Delta C(T)) Method. Methods 25: $402-408$.

Naassila M, Ledent C, and Daoust M (2002) Low ethanol sensitivity and increased ethanol consumption in mice lacking adenosine A2A receptors. $J$ Neurosci 22: 10487-10493.

Nagy LE, Diamond I, Casso DJ, Franklin C, and Gordon AS (1990) Ethanol increases extracellular adenosine by inhibiting adenosine uptake via the nucleoside transporter. J Biol Chem 265:1946-1951.

Parkinson FE, Xiong W, Zamzow CR, Chestley T, Mizuno T, and Duckworth ML (2009) Transgenic expression of human equilibrative nucleoside transporter 1 in mouse neurons. J Neurochem 109:562-572.

Plackett TP and Kovacs EJ (2008) Acute models of ethanol exposure to mice. Methods Mol Biol 447:3-9.

Sharma R, Engemann S, Sahota P, and Thakkar MM (2010a) Role of adenosine and wake-promoting basal forebrain in insomnia and associated sleep disruptions caused by ethanol dependence. J Neurochem 115:782-794.

Sharma R, Engemann SC, Sahota P, and Thakkar MM (2010b) Effects of ethanol on extracellular levels of adenosine in the basal forebrain: an in vivo microdialysis study in freely behaving rats. Alcohol Clin Exp Res 34:813-818.

Sharma R, Sahota P, and Thakkar MM (2014) Role of adenosine and the orexinergic perifornical hypothalamus in sleep-promoting effects of ethanol. Sleep 37:525-533.

Stepanyan TD, Farook JM, Kowalski A, Kaplan E, Barron S, and Littleton JM (2008) Alcohol withdrawal-induced hippocampal neurotoxicity in vitro and seizures in vivo are both reduced by memantine. Alcohol Clin Exp Res 32:2128-2135.

Thakkar MM, Engemann SC, Sharma R, and Sahota P (2010) Role of wakepromoting basal forebrain and adenosinergic mechanisms in sleep-promoting effects of ethanol. Alcohol Clin Exp Res 34:997-1005.

Thompson LF, Eltzschig HK, Ibla JC, Van De Wiele CJ, Resta R, Morote-Garcia JC, and Colgan SP (2004) Crucial role for ecto-5'-nucleotidase (CD73) in vascular leakage during hypoxia. J Exp Med 200:1395-1405.

Wall MJ and Dale N (2013) Neuronal transporter and astrocytic ATP exocytosis underlie activity-dependent adenosine release in the hippocampus. $J$ Physiol 591: $3853-3871$.

Zhang D, Xiong W, Chu S, Sun C, Albensi BC, and Parkinson FE (2012) Inhibition of hippocampal synaptic activity by ATP, hypoxia or oxygen-glucose deprivation does not require CD73. PLoS One 7:e39772.

Zimmermann H, Zebisch M, and Sträter N (2012) Cellular function and molecular structure of ecto-nucleotidases. Purinergic Signal 8:437-502.

Address correspondence to: Dr. Fiona E. Parkinson, SR440-710 William Avenue, Winnipeg MB Canada R3E 0Z3. E-mail: Fiona.Parkinson@umanitoba. ca 